\title{
Focused Ultrasound Therapy
}

National Cancer Institute

\section{Source}

National Cancer Institute. Focused Ultrasound Therapy. NCI Thesaurus. Code C15979.

Minimally invasive procedure for ablating tumors. The primary mechanism of tissue damage is thermal. 